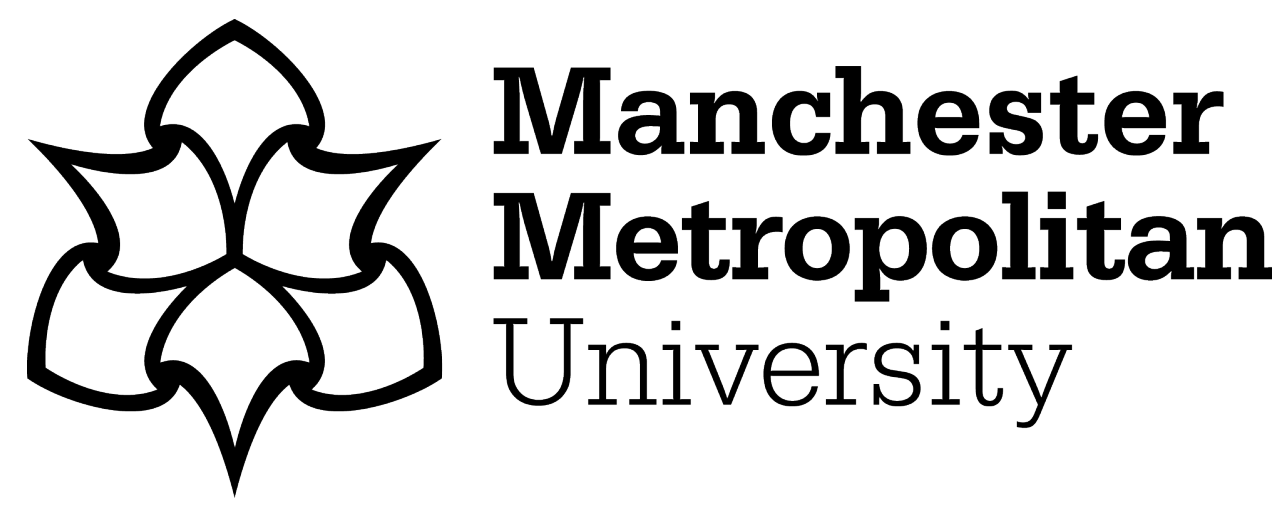

Slater, MJ, Turner, MJ, Evans, AL and Jones, Marc (2018) Capturing hearts and minds: The influence of relational identification with the leader on followers' mobilization and cardiovascular reactivity. The Leadership Quarterly, 29 (3). pp. 379-388. ISSN 1048-9843

Downloaded from: https://e-space.mmu.ac.uk/620547/

Version: Accepted Version

Publisher: Elsevier

DOI: https://doi.org/10.1016/j.leaqua.2017.08.003

Usage rights: Creative Commons: Attribution-Noncommercial-No Derivative Works 4.0

Please cite the published version 
12

(

\section{Capturing Hearts and Minds: The influence of relational identification with the leader on} followers' mobilization and cardiovascular reactivity

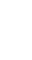

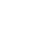

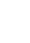

(1)

$$
\text { Matthew J. Slater }{ }^{1} \text {, Martin J. Turner }{ }^{1} \text {, Andrew L. Evans }{ }^{2} \text { and Marc V. Jones }{ }^{1}
$$

\footnotetext{
${ }^{1}$ Centre for Sport, Health and Exercise Research, Staffordshire University, Leek Road, Stoke-onTrent, ST4 2DF, UK.

${ }^{2}$ Directorate of Sport, Exercise, and Physiotherapy, Salford University, Frederick Road Campus, Frederick Road, Salford, M6 6PU, UK.
}

16

7

$$
\text { Author's Accepted Version }
$$

8

Correspondence address: Matthew J. Slater, Centre for Sport, Health and Exercise Research, Staffordshire University, Leek Road, Stoke-on-Trent, ST4 2DF, United Kingdom (e-mail: m.slater@staffs.ac.uk).

7 This research did not receive any external funding. 


\section{Abstract}

2 The influence of relational identification (RI) on leadership processes and the effects of social

3 identity leadership on followers' responses to stress have received scant theoretical and research

4 attention. The present research advances theoretical understanding by testing the assertion that

5 high RI with the leader drives follower mobilization of effort and psychophysiological responses

6 to stress. Two experimental scenario studies (Study 1 and Study 2) support the hypothesis that

7 being led by an individual with whom followers perceive high RI increases follower intentional

8 mobilization. Study 2 additionally showed that high (vs. low) RI increases follower resource

9 appraisals and cognitive task performance. A laboratory experiment (Study 3) assessing

10 cardiovascular $(\mathrm{CV})$ reactivity showed that, compared to neutral (i.e., non-affiliated) leadership,

11 being led by an individual with whom participants felt low RI elicited a maladaptive (i.e., threat)

12 response to a pressurized task. In addition, relative to the low RI and neutral conditions, high RI

13 with the leader did not engender greater challenge or threat reactivity. In conclusion, advancing

14 social identity leadership and challenge and threat theory, findings suggest that leaders should be

15 mindful of the deleterious effects (i.e., reduced mobilization and greater threat state) of low RI to

16 optimize follower mobilization of effort and psychophysiological responses to stress.

17

18 Keywords: social identity; followership; stress; appraisal. 


\section{Capturing Hearts and Minds: The influence of relational identification with the leader on} followers' mobilization and cardiovascular reactivity

A significant and increasing amount of research has supported the positive effect of social identity leadership on outcomes such as trust (Geissner \& van Knippenberg, 2008), influence (Subašić, Reynolds, Turner, Veenstra, \& Haslam, 2011), and follower's job performance (Zhu, He, Trevino, Chao, \& Wang, 2015). Research additionally reports the mediating effect of followers' social identification. For instance, Zhu et al. (2015) found that ethical leadership (whereby leadership is honest, open, trustworthy, caring, and fair; Brown, Trevino, \& Harrison, 2005) had an indirect effect on follower job performance through the mechanisms of identification with both the organization and the leader (relational identification [RI]; Sluss \& Ashforth, 2007). Previous literature has focused on the direct and mediating effects of organizational identification (i.e., the extent to which a follower identifies with the organization; see Haslam, 2004) but has somewhat neglected relational elements of identification (i.e., the extent to which a leader-follower relationship has psychological meaning). Formally, Sluss and Ashforth (2007, p. 15) defined RI as "a (partial) definition of oneself in terms of a given role-relationship — what the relationship means to the individual". In the present article, we contribute to theory by testing the assertion that RI with the leader drives follower mobilization of effort and psychophysiological responses to a pressurized task.

Theory and evidence within the social identity paradigm have demonstrated the positive influence of shared group identification for leadership (see, for reviews, Haslam, Reicher, \& Platow, 2011; Hogg, 2001) and health (see, for reviews, Haslam, Jetten, Postmes, \& Haslam, 2009; Steffens, Haslam, Schuh, Jetten, \& van Dick, 2016). Despite this understanding, theorists and researchers have typically overlooked relational elements of identification (see, for 
1 exceptions, Steffens, Haslam, \& Reicher, 2014; Zhu et al., 2015), and have only more recently

2 focused on intentional mobilization as a pertinent leadership outcome. Further, the social

3 identity approach to health has outlined the positive stress-buffering effects of social support

4 through shared identity (e.g., Haslam \& Reicher, 2006), but has not considered followers'

5 objective (i.e., cardiovascular; CV) stress reactivity as a function of leadership. Accordingly,

6 one of the novel theoretical contributions of the present research is to examine whether

7 leadership, and in particular RI with the leader, is a key determinant of individuals' stress

8 reactivity. In doing so, the present research contributes to both theory (i.e., the social identity

9 approach to leadership and health) and methodology (i.e., by adopting objective CV reactivity measures) through an exploration of how followers' mobilization and CV reactivity to stress

11 (which has far reaching implications for stress in the general population; e.g., workplace stress, 12 see, for an example, Kivimäki et al., 2012) varies as a function of perceived RI with the leader.

Overall, the present research contributes to existing literature in at least three important

14 ways. First, advancing social identity leadership, we examine whether high (vs. low) RI with the

15 leader mobilizes followers towards the leader's vision. Second, we extend social identity

16 approaches (to leadership and health) by examining the effect of RI with the leader - which has

17 been overlooked compared to group/organizational identification — on resource appraisals and

18 objective $\mathrm{CV}$ responses to stress. In doing so, RI with the leader may emerge as a prominent

19 theoretical construct within the social identity approach in reference to individuals' responses to

20 stress. Third, we extend challenge (i.e., adaptive reactivity) and threat (i.e., maladaptive

21 reactivity) theory (Blascovich \& Mendes, 2000; Jones, Meijen, McCarthy, \& Sheffield, 2009) by

22 examining whether social factors, and in particular RI with the leader, differentiates between 
1 individuals' stress reactivity ahead of a pressurized task. In doing so, this research examines the

2 first evidence for the inclusion of leadership factors within challenge and threat theory.

3 Conceptual Background and Hypotheses Development

$4 \quad$ The Social Identity Approach to Leadership

The social identity approach (encompassing both social identity; Tajfel \& Turner, 1979

6 and self-categorization theories; Turner, Hogg, Oakes, Reicher, \& Wetherell, 1987) asserts that

7 individuals derive their sense of self from their individuality (i.e., their personal identity) and

8 from the groups to which they psychologically belong (i.e., their social identities). Evidence

9 points to the importance of understanding and working with individuals' social identities for

10 group functioning (e.g., Haslam, 2004), organizational performance (e.g., Boehm, Dwertmann,

11 Bruch, \& Shamir, 2015), and leadership (see, for reviews, Haslam et al., 2011; Hogg, 2001).

12 Speaking to the importance of these social identity processes for leadership, substantial evidence

13 has found that leadership success hinges upon the development, management, and advancement

14 of a group identity that leaders and followers share.

Developing, managing, and advancing a shared sense of group identity has a positive

16 effect on leadership effectiveness. For example, leaders who embody a group's identity are more

17 likely to be supported (van Dijke \& De Cremer, 2010), trusted (Giessner \& van Knippenberg,

18 2008), and perceived as effective (van Knippenberg \& van Knippenberg, 2005). At the London

192012 Olympic Games successful leaders were more likely to articulate their team's identity,

20 values, and vision in their media communication which may have served to enhance the

21 'specialness' associated with belonging to the team, and mobilize athletes to performance

22 excellence (Slater, Barker, Coffee, \& Jones, 2015). Thus, social identity leadership increases 
1 perceived leadership effectiveness, whilst leaders work to proactively advance group identities

2 by articulating shared values.

Despite the significant and growing research attention examining social identity

4 leadership, the relational aspect of identification has been typically overlooked (Sluss \&

5 Ashforth, 2007). Two exceptions to this omission are the programs of research by Steffens et al.

6 (2014) and Zhu et al. (2015). Steffens and colleagues (2014) examined whether followers' social

7 identification transferred to their identification with the leader in relational terms (i.e., RI).

8 Related to the current research, in experimental and cross-sectional studies, Steffens and

9 colleagues found that compared to low-identified followers, highly identified followers reported

10 increased RI when they shared a group membership with a leader (but not when the leader

11 represented an out-group). High RI was also found to increase charismatic perceptions of the

12 leader. These findings support the "bottom-up" hypotheses that social identification predicts RI

13 with the leader (and not that RI with the leader predicts social identification), while it is also

14 clear that social identification, leader's group affiliation, and perceptions of RI with the leader

15 interact to implicate followers' perceptions of leaders' charisma.

16 The examination of RI with leaders is important because within workplace settings

17 individuals interact with their leader (e.g., line manager) frequently and may feel psychologically

18 closer to them compared to the organization overall (Zhu et al., 2015). This same notion is

19 inherent in high performance settings such as elite sport, where athletes typically engage with

20 their leader (i.e., coach) on a daily basis. Further, in a study of Romanian workplace employees,

21 Zhu et al. (2015) reported that RI with the leader positively predicted job performance (as rated

22 by the followers' supervisors). To build on the work of Steffens et al. (2014) and Zhu et al.

23 (2015) and further understand the importance of RI as a theoretical construct in social identity 
1 leadership there is a need to examine the effect of different levels of RI with the leader on

2 followers' psychology in performance and health terms. This is because whilst perceptions of

3 leader charisma (Steffens et al., 2014) and supervisor-rated job performance (Zhu et al., 2015)

4 have provided valuable insights into the effects of RI, questions remain pertaining to the effect of

5 RI with the leader on psychological constructs holistically under followers' control (e.g., their

6 mobilization of effort) and important constructs related to follower health and well-being (e.g.,

7 CV responses to stress). Accordingly, the present research makes a theoretical contribution to

8 social identity leadership by investigating followers' psychological (i.e., mobilization of effort)

9 and psychophysiological (i.e., self-report and CV reactivity to stress) responses as a function of

10 RI with a leader (e.g., high vs. low).

11 To date, researchers have typically focused on followers' perceptions to assess effective

12 leadership, yet scholars have proposed that researchers should move beyond this (Subašić et al.,

13 2011). In response, leadership researchers have assessed participants' intentional mobilization

14 through, for example, intentions to engage in collective action (Seyranian, 2014), or the amount

15 of time willing to dedicate to an assigned task (Halevy, Berson, \& Galinsky, 2011). To illustrate,

16 Halevy and colleagues (2011) found that visionary leaders increased followers' mobilized

17 collective action (i.e., intentional time). Moving beyond perceptions of leadership effectiveness

18 and focusing on mobilization may increase our understanding of successful leadership and better

19 reflects leadership as an influential process of motivating followers' energies to a collective

20 target (Northouse, 2015). Aligned with these developments, the current research examines

21 followers' intentional mobilization as a function of the theoretically unexplored principle of RI

22 with the leader.

23 H1: High (vs. low) RI with the leader will increase follower intentional mobilization. 
Theory and research support the notion that social identity leadership has a positive effect

2 beyond followers' endorsement of leadership. In a hypothetical scenario study, compared to leaders who used non-inclusive language, leaders who used inclusive language (e.g., "we" and "us") to promote a sense of shared identity elicited greater positive emotion and confidence regarding social change in followers (Seyranian, 2014). This initial evidence implies that leadership that enhances the group's identity (e.g., through inclusive language) is more likely to elicit positive emotions and confidence towards change.

Despite the limited attention paid to followers' emotional response to leadership from a social identity perspective, a significant body of literature exists surrounding social identities and health (Haslam et al., 2009). In a meta-analysis, Steffens and colleagues (2016) found that shared social identification in working groups (and at the organizational level) predicted individuals' experience of better health (i.e., presence of well-being and an absence of stress). Moreover, Haslam and Reicher (2006) reported that individuals' sense of shared identity is positively related to social support and coping with situational stressors. Further evidence has suggested that in a stressful situation the presence of others reduces salivary cortisol (a measure of psychological stress) only when a shared sense of social identification has been established with that individual (Haussen, Kattenstroth, van Dick, \& Mojzisch, 2012). In sum, comparative to social identification and leadership, the links between social identification and health have been subject to less attention from researchers, but this is growing and is contributing to theoretical developments (Steffens et al., 2016). We sought to build on this research and contribute to theoretical developments in both the social identity approach to leadership (Haslam et al., 2011; Hogg, 2001) and health (Haslam et al., 2009; Steffens et al., 2016), by exploring the impact of leadership (and RI with the leader specifically) on individuals' stress responses. 
In the current paper we test the proposition that social identity leadership has a significant

2 role to play in followers' stress response. Specifically, in Study 2 and 3, we examine followers' stress response as a consequence of being led in a pressurized situation by leaders with whom followers perceive high (vs. low) RI. This line of inquiry is important because, theoretically, findings will contribute to our understanding of the social identity approach to leadership and health. Practically too, understanding the effect leaders can have on individuals' stress response (e.g., in the workplace) is of benefit. For example, workplace stress is currently in sharp focus given the predictive links between workplace stress and life-threatening illnesses (e.g., CV disease; Kivimäki et al., 2012).

\section{Stress Reactivity}

Stress is not inherently bad and individuals do not necessarily respond negatively to, and perform poorly, under stress. One approach that outlines how a person may respond positively and negatively under stress is the biopsychosocial (BPS) model of challenge and threat (Blascovich \& Mendes, 2000). Challenge and threat are two distinct psychophysiological responses to stressors which occur in motivated performance situations where success is important and it is perceived (demand appraisals) that there is a danger to esteem, uncertainty, and a requirement for effort (see Blascovich, Mendes, Vanman, \& Dickerson, 2011; Seery, 2011). The individual also makes resource appraisals about the extent to which they can cope with the situation. In the present paper we draw on the resource appraisals outlined by the Theory of Challenge and Threat States in Athletes (TCTSA; Jones et al., 2009) which are the extent to which a person feels self-efficacious in that situation, in control over their abilities, and to what extent they are focused on what can be achieved (approach goals) versus what could be lost (avoidance goals) in the situation. A challenge state occurs if the resources are perceived to 
match or exceed the demands, and a threat state occurs if the demands are perceived to outweigh the resources.

Theory (Blascovich \& Mendes, 2000) and research (Tomaka, Blascovich, Kibler, \& Ernst, 1997), also proposes physiological concomitants of challenge and threat states that draw on hemodynamic CV markers to objectively indicate both states. We chose this approach as it explores whether individuals' level of stress (irrespective of whether it is high or low) can be perceived as either adaptive (i.e., challenge) or maladaptive (i.e., threat). Specifically within challenge and threat theory, a challenge state is accompanied by increased Sympathetic AdrenoMedullary (SAM) activity accompanied by catecholamine release (epinephrine and norepinephrine). This is indexed by increased heart rate (HR; heart beats per minute[bpm]) and cardiac output ( $\mathrm{CO}$; litres of blood pumped from the heart per minute[1/min]), and decreased total peripheral resistance (TPR; sum of the resistance of all peripheral vasculature in the systemic circulation[dyn.s.cm-5]). A challenge response is proposed to promote efficient energy use through increased blood flow to the brain and muscles, higher blood glucose levels (fuel for the nervous system) and an increase in free fatty acids that can be used by muscles as fuel (e.g., Dienstbier, 1989). A threat state is similarly marked by increased SAM activity, but is also characterized by increased Pituitary Adreno-Cortical (PAC) activity accompanied by cortisol release. A threat state is evidenced by increased HR, but with a minimal change, stabilization, or small decrease in $\mathrm{CO}$, and an increase or stabilization in TPR. Consequently, in a threat state PAC activity tempers the positive effects of SAM activity therefore the mobilization of energy is less efficient than in a challenge state as blood flow (and therefore glucose) to the brain and muscles is restricted (e.g., Dienstbier, 1989). 
In a challenge state, the proposed underlying SAM activation is fast-acting and represents

2

the efficient mobilization of energy for action, reflected by increased $\mathrm{CO}$ and decreased TPR reactivity. A threat state reflects PAC (and SAM) activation and is considered a "distress system" reflected by decreased CO and increased TPR reactivity (Blascovich \& Mendes, 2000). A threat state is considered maladaptive in motivated performance situations, and growing research supports the $\mathrm{CV}$ indicators of challenge and threat states (indexed by $\mathrm{HR}, \mathrm{CO}$, and TPR) in response to motivated performance situations (see Blascovich et al., 2011; Seery, 2011; for reviews). Indeed, research has shown that a challenge state is associated with superior performance compared to a threat state in cognitive (Turner, Jones, Sheffield, \& Cross, 2012) and motor (Turner et al., 2013) tasks. Yet, the role of leadership, and how the leader is perceived, in determining individuals' challenge and threat states, indexed by CV reactivity, is not currently considered by the TCTSA (Jones et al., 2009), or within broader challenge and threat theory (Blascovich \& Mendes, 2000). This is specifically addressed in the present research. Whether and to what extent leaders can influence challenge and threat states may have important implications for theoretical developments in challenge and threat and for follower stress reactivity, performance, and well-being.

H2: High (vs. low) RI with the leader will produce a challenge cognitive appraisal in followers on approach to a pressurized task.

H3: High (vs. low) RI with the leader will produce a challenge state (adaptive CV reactivity) in followers on approach to a pressurized task.

\section{Overview of the Studies}

Study 1 is the first study to examine the effect of RI with the leader on followers' mobilization, whilst Studies 2 and 3 are the first to explore the effect of RI with the leader on 
1 followers' appraisals and CV reactivity ahead of a pressurized task. In Study 1, we used an

2 experimental vignette methodology (EVM; Aguinis \& Bradley, 2014) to manipulate RI with the

3 leader (high vs. low) to examine followers' intentional mobilization. In adopting EVM we

4 followed the nine recommendations suggested by Aguinis and Bradley (2014) and use a 'paper

5 people study' approach. We diverted from Aguinis and Bradley's (2014) preference for within-

6 subject designs, nonetheless, we adhered to suggestions to provide sufficient contextual

7 information to participants and analyzed data using analyses of variance (ANOVA). In a second

8 EVM, Study 2 manipulated RI with the leader (high vs. low; and added a third, neutral,

9 condition) to examine followers' intentional mobilization and resources appraisals ahead of a

10 pressurized cognitive task. Building on the EVM adopted in Study 1 and 2, with the same three

11 conditions, Study 3 reports a laboratory experiment that examined the effect of RI with the leader

12 on followers' CV stress reactivity (i.e., $\mathrm{HR}, \mathrm{CO}$, and TPR as indicators of challenge and threat;

13 Blascovich \& Mendes, 2000; Tomaka et al., 1997) ahead of a pressurized memory task.

\section{Study 1}

\section{Participants and design}

Ninety athletes $\left(M_{\mathrm{age}}=20.27 \pm 4.15 ; 66\right.$ males $)$ that had experience of sport competition $\left(M_{\text {years }}=9.78 \pm 4.59\right)$ from recreational $(51 \%)$ to national/international $(20 \%)$ level completed the study. The study adopted an EVM (Aguinis \& Bradley, 2014) and used a betweenparticipant design with two conditions; high RI and low RI.

\section{Procedure and measures}

Following institutional ethical approval participants provided informed consent and demographic information before reading one of two scenarios. Data were collected in undergraduate lectures from students studying sport and exercise science related degrees in the 
1 United Kingdom. In both conditions, participants read a coach-athlete scenario that described

2 the participant as a member of a sports team where they felt a great sense of belonging (to

3 strengthen social identification) and had one training session remaining before a competitive

4 match. The coach had requested that the participant spent 15 hours on a task in preparation for

5 the training session. In the high RI condition participants were told that: "your team has a strong

6 connection and bond with your coach" (to strengthen RI with the leader). In contrast, RI was

7 mitigated in the low RI condition by detailing that a coach from a rival team will be taking the

8 training session and participants had "no connection with the rival coach". The remainder of the

9 scenario was the same. The high and low RI scenarios can be seen in the Supplementary File

10 (S1). Participants then completed the following measures on a 7-point Likert scale ranging from

111 (do not agree at all) to 7 (completely agree) unless otherwise stated.

Manipulation checks. To ascertain whether participants were successfully immersed in

13 the scenario we measured group identification with three-items (cf., Haslam, 2004). Participants

14 were asked the extent to which: (1) "you feel a strong connection with the group"; (2) "you

15 identify strongly with the group"; and (3) "you feel no connection with the group" (reverse

16 scored). The Cronbach alpha for this scale was 0.81. A second manipulation check assessed $R I$

17 with the leader with the same three-items with "coach" substituted for "group" (e.g., "you

18 identify strongly with the coach"). The Cronbach alpha for this scale was 0.77 .

Mobilization. Two measures of mobilization were used. First, a five-item scale assessed intentional mobilization (e.g., "you want to make a distinct contribution to the final training

21 session to impress the coach"; $\alpha=0.87$ ), and second, a single item commonly used (e.g., Halevy

22 et al., 2011; Seyranian, 2014) assessed participants' mobilization hours they were willing to 
1 dedicate to the task ("How many hours [out of 15] would you be willing to dedicate to the

2 preparation task set by the coach?")

3 Results

4 Manipulation checks. As expected, two independent samples $t$-tests revealed no

5 significant differences, $t(88)=-0.35, p=0.730$, in group identification between the high $\mathrm{RI}(M=$

$65.75 \pm 0.99)$ and low RI $(M=5.82 \pm 1.05)$ conditions, but a significant difference in $R I$ with the

7 leader, $t(88)=7.36, p<0.001$, with the high RI condition reporting higher levels $(M=5.30 \pm$

8 0.92) than the low RI $(M=3.69 \pm 1.15)$ condition.

9 Mobilization. Multivariate analysis of variance (MANOVA) indicated that intentional mobilization and mobilization hours varied significantly as a function of condition (high RI vs. low RI), Wilks' $\Lambda=0.83, F(2,87)=8.76, p<0.001, \eta_{p}^{2}=0.17$. Follow-up simple comparisons indicated that the high RI condition reported greater intentional mobilization $(M=5.71 \pm 0.77, p$ $<0.001$ ) and mobilization hours (high RI: $M=11.00 \pm 3.21, p=0.048$ ) compared to the low RI condition $\left(M_{\text {likert }}=4.82 \pm 1.20 ; M_{\text {hours }}=9.27 \pm 4.84\right)$. Correlations between all study variables are displayed in Table 1.

[insert Table 1 about here]

\section{Discussion}

In support of $\mathrm{H} 1$, followers reported greater intentional mobilization when high (vs. low) levels of RI with the leader were perceived. Advancing social identity perspectives, compared to low RI, data indicated that participants would be willing to practice for $18.7 \%$ longer on a task related to the leader's vision when they perceived high RI with the leader. This study sought to extend social identity leadership and further address calls for leadership effectiveness measures that go beyond perceptions of leaders by focusing on followers' intentional mobilization as a 
1 function of the unexplored principle of RI with the leader. However, while a plausible sporting

2 situation was used, Study 1 involved hypothetical identification artificially created for the

3 experiment. Thus, in Study 2 we recruited a sample allowing for the examination of

4 participants' natural group identification preceding a motivated performance situation, where RI

5 with the leader could be assessed alongside participants' approach to a meaningful and stressful

6 event.

7

8

9

11

12

13

14

15

16

17

18

19

20

21

22

23

\section{Study 2}

Study 1 data suggest that RI with the leader has implications for how followers' engage in intentional mobilization. Extending social identity leadership, these findings show that in motivated performance situations, follower perceptions of high (vs. low) RI with the leader increase leaders' ability to mobilize the group (i.e., by intending to dedicate increased hours).

How an individual then approaches a motivated performance situation can be determined by their cognitive appraisal of the upcoming event. One framework that explicitly outlines resource appraisals in motivated performance situations is the TCTSA (Jones et al., 2009). Appraising a motivated performance situation as a challenge (high confidence, high control, approach focus) will evince an adaptive stress response, which has been associated with positive emotional, physical, and behavioral (performance) outcomes (Jones et al., 2009). The significant influence of leadership on followers' commitment has been long-researched in the social identity paradigm (see, for a review, Haslam et al., 2011), while within challenge and threat literature previous evidence has found that it is possible for others to influence challenge and threat states through instructions (Turner, Jones, Sheffield, Barker, \& Coffee, 2014). Nevertheless, the effect of social identity leadership on cognitive appraisal is unknown and not accounted for in challenge and threat theory (e.g., TCTSA; Jones et al., 2009). Therefore, to build on Study 1 and to contribute 
1 theoretically to social identity and challenge and threat approaches, we conducted a second study

2 that used undergraduate students' natural group identification (with their university) and

3 examined participants' responses to leaders, varying in RI, approaching a pressurized motivated

4 performance situation. We also sought further support for H1 by examining participants'

5 mobilization towards the task (as in Study 1), and their future behavioral intentions (via hours

6 practicing and percentage effort).

$7 \quad$ Method

Participants and design. Using an EVM (Aguinis \& Bradley, 2014), a between-

9 participant design involved 85 undergraduate students $\left(M_{\text {age }}=20.79 \pm 3.90 ; 65\right.$ males $)$ from a British University. Participants were randomly assigned to a high RI, low RI, or neutral (i.e., 11 non-affiliated) condition.

Procedure. Following institutional ethical approval participants gave informed consent

13 before completing a demographic questionnaire. Data were collected in undergraduate lectures

14 from students studying sport and exercise science related degrees. Participants read a vignette

15 written by a leader described as a Professor either belonging to the same university as the

16 participant (high RI with the leader), a rival university (low RI with the leader), or having no

17 affiliation (neutral). The vignettes informed participants that the leader was a Professor and was

18 collecting data at the participants' university and a rival (and geographically local) university.

19 Further, participants were instructed that the study aimed to examine differences in concentration

20 ability between their university and the rival university. Thus, a competition between the

21 participants' university (the in-group) and the rival university (the out-group) was created. To

22 further elicit a stress response, ego-threatening instructions were used with the vignettes stating

23 that: (1) the participant's score will contribute to their university's overall score to be compared 
1 with the rival university; (2) a league table of the best performing to the worst performing

2 individuals will be created and seen by all participants at the end of the project; and (3) very high

3 levels of effort will be required to complete the task. The full vignettes can be seen in the

$4 \quad$ Supplementary File (S2). After reading the vignettes, participants completed social

5 identification (e.g., RI with the leader) and challenge and threat-related measures (e.g., resource

6 appraisals of self-efficacy, control, and achievement goals), before a cognitive task. After the

7 task, participants were informed that they would be required to return for a second trial in a

8 week's time. Participants were informed that concentration ability can be improved and that

9 "you can practice this test on this website" (the website was hypothetical). Participants then

10 indicated how many hours and the percentage effort they would practice to improve their

11 concentration skills over the next 7 days. Participants were then informed that they were not

12 required to return next week and were fully debriefed.

Measures. Measures were the same as those in Study 1, but with the upcoming competition rephrased to "the upcoming Concentration Test". In addition, self-report measures of resources appraisals in relation to the concentration task, task importance, the cognitive task

16 (performance measure), and post-data collection hours and percentage effort measures were 17 gathered, as follows:

Achievement goals. The Achievement Goals Questionnaire (AGQ: Conroy, Elliot, \& Hofer, 2003) measures performance approach goals (PAp), performance avoidance goals (PAv), mastery approach goals (MAp), and mastery avoidance goals (MAv). In-line with previous research (e.g., Turner et al., 2013), for brevity, the AGQ was reduced to 4 items (one item for

22 each subscale). Participants responded in reference to the upcoming Concentration Test on a 723 point Likert-scale ranging from 1 (not at all true) to 7 (very true). 
Self-efficacy. Participants responded to one item, "with reference to the upcoming Concentration Test, to what extent do you feel confident that you can score highly?" The participants responded on a 9-point Likert-scale ranging from 1 (not at all) to 9 (completely).

Perceived control. Adapted from the Academic Control Scale (Perry, Hladkyj, Pekrun, \& Pelletier, 2001), participants were asked to rate how much they agreed that "you have control over the factors that will determine your performance", on a 7-point Likert-scale ranging from 1 (no control) to 7 (total control).

Task importance. Participants were asked how important doing well in the upcoming Concentration Test was for them on a 6-point Likert-scale ranging from 0 (not at all) to 5 (very much so).

Cognitive task performance. The cognitive task consisted of a grid of 100 squares (arranged 10x10) with each square containing a two-digit number (from 00 to 99), in a random order. Participants' were to find and mark as many consecutive numbers as possible within a 1minute period, starting from 20. The number of consecutive numbers marked by each participant was recorded.

Future hours and percentage effort intentions. The number of hours participants were willing to dedicate to practice was measured using a single-item: "Over the next 7 days, how many hours are you willing to dedicate to practicing for the Concentration Test?" As was their effort: "Using a percentage, in each practice session how much effort will you put in to practicing the Concentration Test over the course of next week?"

\section{Results}

Manipulation checks. As identification with the in-group (their university) was a prerequisite, eight participants were removed due to low group identification with their 
1 university $(M<3.00)$. Seventy-seven participants were included in the following analyses (high RI: 25, low RI: 26, neutral: 26). There were no differences in group identification (with the ingroup or out-group) between the three conditions, Wilks' $\Lambda=0.93, F(4,146)=1.36, p=0.250$. As expected, ANOVA revealed differences between the conditions in RI with the leader, $F(2$, $74)=10.98, p<0.001$. Specifically, the high RI condition $(M=3.68 \pm 0.99)$ reported greater RI with the leader compared to both the low RI $(M=2.27 \pm 1.25 ; p<0.001)$ and neutral $(M=2.52$

$7 \quad \pm 1.17 ; p=0.002)$ conditions.

Task importance. Task importance is a prerequisite for challenge and threat states, therefore it was necessary to determine whether participants felt that the Concentration Test was important. A one-sample $t$-test indicated that all conditions reported the concentration task to have high importance (i.e., significantly different to zero; $t(76)=14.65, p<0.001$ ). There was a significant difference in importance across conditions, $F(2,74)=3.63, p=0.031, \eta^{2}{ }_{p}=0.09$. Specifically, the low RI condition $(M=2.65 \pm 1.35)$ reported greater importance than the neutral condition $(M=1.73 \pm 1.19 ; p=0.044)$.

Mobilization towards task. ANOVA indicated that mobilization varied significantly as

16 a function of condition (high RI vs. low RI vs. neutral), $F(2,74)=9.98, p<0.001, \eta^{2} p=0.21$.

17 Follow-up simple comparisons indicated that the high RI condition $(M=4.99 \pm 0.86)$ reported

18 greater mobilization than the low RI $(M=4.18 \pm 1.18 ; p=0.022)$ and neutral $(M=3.69 \pm 1.07 ; p$

$19<0.001)$ conditions. All descriptive statistics can be seen in Table 2.

21 did not significantly vary as a function of condition (high RI vs. low RI vs. neutral), $F(2,74)=$ $22.14, p=0.872$, (high RI $M=0.88 \pm 1.09$; low RI $M=0.84 \pm 0.94$; neutral $M=0.72 \pm 1.31$ ). A 
1 function of condition (high RI vs. low RI vs. neutral), $F(2,74)=1.33, p=0.271, \eta^{2} p=0.04$. As displayed in Table 2, the high RI condition reported (non-significantly) greater percentage effort intentions $(M=57.40 \pm 41.86)$, compared to the low RI $(M=44.62 \pm 36.22)$ and neutral conditions $(M=39.21 \pm 43.98)$.

[insert Table 2 about here]

Achievement goals. MANOVA indicated that $P A p, P A v, M A p$, and $M A v$ varied significantly as a function of condition (high RI vs. low RI vs. neutral), Wilks' $\Lambda=0.75, F(8$, $142)=2.73, p=0.008, \eta^{2} p=0.13$. Follow-up simple comparisons indicated that the high RI condition reported: $(1)$ greater $P A p(M=6.00 \pm 1.15)$ and $M A p(M=5.44 \pm 1.12)$ goals compared to the low RI condition $(P A p M=4.96 \pm 1.46, p=0.043 ; M A p M=4.50 \pm 1.27, p=$ 0.041); and (2) greater $P A p, M A p$, and $P A v$ (high RI $M=4.08 \pm 1.63$ ) goals than the neutral condition $(P A p M=4.42 \pm 1.74, p=0.001 ; M A p M=4.00 \pm 1.55, p=0.001 ; M A v M=2.77 \pm$ $1.66, p=0.029)$.

Self-efficacy and control. MANOVA indicated that self-efficacy and control varied significantly as a function of condition (high RI vs. low RI vs. neutral), Wilks' $\Lambda=.78, F(4,146)$ $=3.91, p=0.001, \eta^{2}=0.12$. Specifically, the high RI condition $(M=6.88 \pm 0.88)$ reported greater self-efficacy compared to the low RI $(M=5.96 \pm 1.31, p=0.013)$ and neutral $(M=5.65 \pm$ $1.21, p=0.001)$ conditions. No follow-up differences were observed for control.

Cognitive task performance. ANOVA indicated that cognitive task performance varied significantly as a function of condition (high RI vs. low RI vs. neutral), $F(2,74)=7.33, p=$ $0.001, \eta_{p}^{2}=.17$. Specifically, the high RI condition $(M=10.28 \pm 2.49)$ performed better than the low RI $(M=7.50 \pm 2.98, p=0.004)$ and neutral conditions $(M=7.46 \pm 3.44, p=0.004)$. Correlations between all study variables are displayed in Table 3. 
[insert Table 3 about here]

\section{Discussion}

Study 2 sought to examine the impact of manipulating followers' RI with the leader on

4 their mobilization and challenge and threat resource appraisals. In-line with $\mathrm{H} 1$ and Study 1, we

5 found that when participants were led to perceive high (rather than low) RI with the leader they

6 reported greater mobilization. Further, we found that this mobilization ahead of an upcoming

7 task was not maintained in participants' future mobilization intentions (i.e., hours and percentage

8 effort over the next week).

9 Advancing challenge and threat theory, an additional aim of Study 2 was to examine the

10 impact of manipulating followers' RI with the leader on their resource appraisals and

11 performance on a pressurized cognitive task. Supporting H2, we found that, relative to the low

12 RI and neutral conditions, the high RI condition reported greater self-efficacy and approach

13 goals, yet greater performance avoidance goals. Taken together these data suggest that,

14 compared to the low RI and neutral conditions, the high RI condition had greater perceptions of

15 challenge, performed better on the cognitive task, and were more willing to devote immediate

16 discretionary effort, although this willingness did not extend to increased discretionary effort in

17 the week following the task. Finally, participants in the low RI condition perceived the task to

18 be more important than the neutral condition, but not the high RI condition. It is not completely

19 unexpected that the neutral condition reported lower importance because this condition did not

20 involve an in-group or out-group leader that was affiliated to one of the competing universities.

21 Crucially, though, all conditions rated the Concentration Test to be significantly important to

22 them. 
While Study 2 indicates differences in follower responses to stress as a function of RI with the leader, previous research has indicated that these self-report measures are inconsistent with objective stress markers of challenge and threat (Turner et al., 2012). Further, both Study 1 and 2 adopted EVM designs. Accordingly, in Study 3 we conducted a laboratory experiment to capture followers' $\mathrm{CV}$ responses (i.e., HR, TRP, and CO as indicators of challenge and threat) ahead of a pressurized task across the same RI with the leader conditions used in Study 2.

\section{Study 3}

Study 2 data indicated that in response to a leader with whom participants perceived high RI (vs. low RI or no-affiliation), greater resource appraisals (except higher performance avoidance goals), akin to a challenge state, were reported. In theory and research, challenge and threat states are indexed using CV indices of HR, CO, and TPR (for reviews see Blascovich \& Mendes, 2000; Seery, 2011, and for research studies see Tomaka et al., 1997; Turner et al., 2012; 2013 ; 2014), providing an objective assessment of how a person is approaching a task.

Therefore, to advance Study 2 and challenge and threat theory, a laboratory experiment examined undergraduate students' CV response to a motivated performance situation, led by a leader with whom they perceived high RI vs. low RI vs. no affiliation. In this way, it was possible to understand the effects of leadership on objective stress markers on approach to a motivated performance (pressurized) situation.

\section{Method}

Participants and design. In a between-participant design 83 undergraduate students $\left(M_{\text {age }}=20.78 \pm 3.55 ; 58\right.$ males $)$ from a British University were randomly assigned to a high RI, low RI, or neutral (non-affiliated) condition. 
Procedure. Following institutional ethical approval participants gave informed consent

before completing a demographic questionnaire. Participants were randomly assigned to attend the laboratory and initially completed two baseline trials of a working memory task (the backwards digit-span task [BDS]; Berman, Jonides, \& Kaplan, 2008). Participants' accuracy of responses were recorded. Participants were given further (false) information regarding the study, informing them that the researchers were collecting data at the participants' university and a rival (geographically local) university. To increase the salience of participants' university identity, participants were given a lanyard displaying their university's logo.

Next, participants were connected to a Finometer Pro, which records beat-to-beat CV activity. The Finometer Pro records CV data through an inflating finger cuff around the middle finger of the non-dominant hand. Participants sat still for five-minutes while they acclimatized to the Finometer Pro and the laboratory environment to minimize the effects of white-coat hypertension. Following that, to gain baseline CV data participants were monitored for a further five-minute resting period, after which participants viewed a video from a leader described as a Professor either belonging to the same university as the participant (high RI with the leader), a rival university (low RI with the leader), or having no affiliation (neutral). The same person acted as the leader in each video ${ }^{1}$. In the video, participants were (falsely) instructed that the study aimed to examine differences in memory ability between their university and the rival university. Thus, a competition between the participants' university (the in-group) and the rival university was created (the out-group). The same ego-threatening instructions used in Study 2 were replicated here. Following the video, CV responses were recorded for a further twominutes, after which participants completed social identity and challenge and threat-related selfreport measures. Finally, participants completed the BDS (Berman et al., 2008). 
Measures. Manipulation checks of identification and importance remained the same as in Study 2 with the addition of participants' CV reactivity and working memory capacity.

CV reactivity. A Finometer Pro was used to measure all $\mathrm{CV}$ responses. The Finometer Pro measures CV indices beat-to-beat. In-line with challenge and threat theory (Blascovich \& Mendes, 2000; Jones et al., 2009) and research (e.g., Tomaka et al., 1997; Turner et al., 2012; 2013; 2014), only the parameters related to challenge and threat assessment were processed; HR (bpm), $\mathrm{CO}\left(1 /\right.$ minute), and TPR (dyn.s.cm $\left.{ }^{-5}\right)$. CO is derived from stroke volume (SV) and HR $(\mathrm{CO}=\mathrm{SV} x \mathrm{HR})$, and TPR is derived from mean arterial pressure (MAP; average blood pressure) and $\mathrm{CO}(\mathrm{TPR}=[\mathrm{MAP} / \mathrm{CO}] \times \mathrm{x} 8)$. In-line with previous research (e.g., Blascovich et al., 2004; Turner et al., 2013), HR was measured as a prerequisite for challenge and threat states and therefore acted as a manipulation check that participants were engaged in the task. Next, we created a single challenge and threat index, which is a latent variable, by converting $\mathrm{CO}$ and TPR reactivity values into $z$ scores and summing them. $\mathrm{CO}$ was assigned a weight of +1 while TPR was assigned a weight of -1 , so that larger values reflected challenge reactivity. The index accounts for the interrelatedness of $\mathrm{CO}$ and TPR reactivity measures. A positive index indicates challenge, whilst a negative index indicates threat.

Cognitive function. To assess cognitive function the BDS, a measure of working memory, was used (Berman et al., 2008). Participants were read a sequence of three to nine digits and asked to repeat them in reverse order. This was repeated up to 14 times (two repetitions of each digit span) and stopped after two consecutive failures. The length of the longest correct sequence prior to two consecutive failures provided a measure of cognitive function (i.e., higher scores indicate better cognitive function). Participants' accuracy score between three and nine digit span was recorded. 


\section{Results}

Manipulation checks. Five participants were removed from analyses (probed for suspicion/requested to be withdrawn), leaving a final sample of 78 (high $\mathrm{RI}=26$, low $\mathrm{RI}=24$, neutral $=28)$. For a further three participants (high $\mathrm{RI}=1$ and neutral $=2) \mathrm{CV}$ data were unobtainable due to equipment malfunction, all other measures were retained. Other manipulation checks were as follows:

Heart rate. Demonstrating participant task engagement, a paired-samples $t$-test indicated a significant increase in heart rate from baseline $(M=72.54 \pm 11.02)$ to instructions $(M=74.37$ $\pm 11.11), t(74)=4.88, p<0.001$. As expected, ANOVA indicated heart rate change did not significantly vary as a function of condition (high RI vs. low RI vs. neutral), $F(2,72)=1.21, p=$ 0.304 .

Task importance. A one-group $t$-test demonstrated that participants rated task importance as significantly different from $0, t(77)=23.17, p<0.001$. ANOVA indicated importance did not vary significantly as a function of condition (high RI $M=3.08 \pm 0.89$; low RI $M=2.96 \pm 1.12 ;$ and neutral $M=2.57 \pm 1.20), F(2,75)=1.62, p=0.205$

Group identification. There were no differences in group identification (with the ingroup or out-group) between the three conditions, Wilks' $\Lambda=0.98, F(4,148)=0.40, p=0.806$. Please see Table 4 for all descriptive statistics.

$\boldsymbol{R I}$ with the leader. ANOVA indicated $R I$ with the leader varied significantly as a function of condition (high RI vs. low RI vs. neutral), $F(2,75)=7.04, p=0.002$. Specifically, the high RI condition $(M=4.23 \pm 1.66)$ reported significantly greater $R I$ with the leader compared to the low RI condition $(M=2.50 \pm 1.59, p=0.001)$, and non-significantly greater $R I$ with the leader than the neutral condition $(M=3.29 \pm 1.65, p=0.111)$. In sum, the mean scores 
1 for RI with the leader were of the magnitude expected for each condition. All descriptive

2 statistics can be seen in Table 4.

[Insert Table 4 about here]

\section{Main analyses.}

CV reactivity. ANOVA indicated the challenge and threat index varied significantly as a function of condition (high RI vs. low RI vs. neutral), $F(2,72)=4.55, p=0.014$. As displayed in Table 2, follow up simple comparisons revealed that the neutral condition $(M=0.76 \pm 1.83)$ displayed a greater level of challenge compared to the low RI condition (who displayed threat $M$ $=-0.68 \pm 1.98, p=0.012)$, but not compared to the high RI condition $(M=-0.14 \pm 1.25, p=$ 0.193).

Cognitive function. ANOVA indicated cognitive function did not vary significantly as a function of condition (high RI vs. low RI vs. neutral), $F(2,75)=0.17, p=0.849$ (high RI $M=$ $5.96 \pm 1.46$; low RI $M=6.21 \pm 1.56$; neutral $M=6.18 \pm 1.96)$. Correlations between all study variables are displayed in Table 5.

[insert Table 5 about here]

\section{Discussion}

Study 3 sought to examine the impact of manipulating followers' RI with the leader on followers' CV reactivity ahead of a pressurized task. In partial support of $\mathrm{H} 3$, we found that, compared to a leader with whom participants felt low RI (who displayed a threat state), being led by a neutral (i.e., non-affiliated) leader engendered an adaptive CV response (i.e., a greater challenge state). Contrary to expectations, we found no differences in challenge or threat between participants in the high RI condition relative to both the low RI and neutral conditions. Thus, leadership from an individual with no affiliation indicated the most adaptive CV reactivity 
1 profile (i.e. greatest challenge), while leadership from an individual with whom participants felt

2 low RI produced the most maladaptive $\mathrm{CV}$ reactivity profile (i.e., greatest threat). No

3 differences in cognitive function were found.

4

\section{General Discussion}

The current research sought to examine the impact of RI with the leader on follower mobilization, resource appraisals, and CV responses ahead of a pressurized task. Across three experiments and a variety of data collection methods including self-report, $\mathrm{CV}$, and cognitive performance measures, we broadly found consistent evidence for our hypotheses. First, in-line with H1, we found that when followers perceive high (vs. low) RI with the leader this fosters intentional task mobilization (Studies 1 and 2). Second, in-line with H2, relative to low RI and neutral leadership, high RI with the leader produced greater resource appraisals and performance on a pressurized cognitive task (Study 2). Third, in partial support of H3, compared to neutral leadership, being led by an individual with whom participants felt low RI elicited a maladaptive (i.e., threat) $\mathrm{CV}$ response to a pressurized task (Study 3). Yet, contrary to H3, relative to the low RI and neutral conditions, high RI with the leader did not engender greater challenge or threat

$$
\text { CV reactivity. }
$$

\section{Theoretical Implications}

The present studies contribute to theoretical developments in at least three important ways. First, advancing social identity leadership (see Haslam et al., 2011; Hogg, 2001), Studies 1 and 2 provide evidence that high (vs. low) RI with the leader mobilizes followers towards the leader's vision during a task. Participants in Study 2 were mobilized towards what matters now (i.e., the upcoming Concentration Test), but no differences were observed between conditions for future intentional mobilization (i.e., during the following week). Previously, Subašić et al. 
1 (2011) argued that scholarly developments should move beyond focusing on followers'

2 perceptions of leader effectiveness by measuring variables such as intentional and objective

3 mobilization (see Halevy et al., 2011; Seyranian, 2014). Beginning to address these calls, Zhu et

4 al. (2015) found that RI with the leader positively predicted job performance (as rated by

5 followers' supervisors). To our knowledge, RI with the leader has not been previously studied as

6 a variable that differentiates between followers' mobilization of effort, and thus our findings

7 provide a more specific account of the psychological consequences for followers across different

8 levels of RI with the leader. In particular, our evidence extends social identity leadership by

9 reporting that levels of intentional mobilized effort, which are at the heart of leadership (Haslam

10 et al., 2011), are greater when followers' perceive high (vs. low) RI with their leader. These

11 findings demonstrate that RI with the leader should be considered within social identity

12 leadership in addition to, and alongside, group/organizational identification. Here to, there are

13 explanations related to other leadership approaches, such as leader-member exchange (LMX)

14 theory, which primarily focuses on the dyadic relationship between leader and follower. To

15 illustrate, meta-analytical reviews have found that the quality of the leader and follower

16 relationship positively predicts followers' commitment, job satisfaction, and performance

17 (Gerstner \& Day, 1997).

Second, and building on the social identity approach to leadership (Haslam et al., 2011;

Hogg, 2001) and health (Haslam et al., 2009), the current research delineates the effects of RI

20 with the leader on followers' cognitive appraisals and CV stress responses. Extending challenge

21 and threat theory (Blascovich \& Mendes, 2000; Jones et al., 2009) our findings provide evidence

22 that followers who perceive high (vs. low) RI with their leader report greater approach goals,

23 performance avoidance goals, and self-efficacy, suggesting a higher appraisal of challenge 
1 (Study 2). Empirically too, these findings extend previous research that has found social

2 identification positively predicts perceived control across a range of groups (e.g., political,

3 academic) and countries (Greenaway et al., 2015), by capturing differences in all resource

4 appraisals within challenge and threat theory (Jones et al., 2009) as a function of RI with the

5 leader.

Third, in reference to CV reactivity, Study 3 showed that leadership from an individual

7 who participants perceived low RI evinced a threat state compared to a challenge state

8 engendered by a neutral leader. These findings suggest that in motivated performance

9 (pressurized) situations there are deleterious effects on follower CV reactivity when being led by

10 an individual that group members feel little RI with. This is an important finding as it

11 demonstrates that follower $\mathrm{CV}$ challenge and threat states (as indexed by CO and TPR reactivity)

12 vary as a function of perceived RI with the leader. This finding represents a theoretical

13 development in that leadership is not currently, but may be, considered within theoretical

14 approaches to challenge and threat (e.g., Blascovich \& Mendes, 2000; Jones et al., 2009).

Theory and research show that, compared to threat responses, challenge responses are associated with superior performance in cognitive (Turner et al., 2012) and motor (Turner et al.,

17 2013) tasks. This effect on cognitive function was not evident in Study 3, but was found in the

18 cognitive task completed in Study 2 with the high RI condition performing better than the low RI 19 and neutral conditions. There are a couple of potential explanations for these findings. First, in

20 Study 2 the greater resource appraisals reported in the high RI (vs. low RI and neutral) condition

21 suggests that these participants were psychologically more equipped to perform on the cognitive

22 task (i.e., greater self-efficacy and approach goals). Significant correlations between both MAp

$23(r=0.27)$ and self-efficacy $(r=0.30)$ and cognitive performance in Study 2 provide some 
1 support for this explanation (see Table 3). Second, this finding could be due to the different

nature of the tasks. The greater mobilization of effort (relative to the low RI and neutral conditions) displayed in Study 2 may have aided the participants' performance on the cognitive task by motivating participants in the high RI condition to direct extra attentional resources to the task, which involved scanning the grid for the correct numbers and processing the information quickly. However, Study 3 used the BDS as the task and it is less clear how extra mobilization of effort may enhance working memory, and in particular, lead to distinct performance differences between the three conditions in which all participants were motivated to perform. In sum, effects on performance were mixed and future research may wish to further investigate the relationships between RI with the leader, resource appraisals/challenge and threat, and performance in more ecologically valid settings.

Interestingly, in Study 3, non-affiliated leadership evidenced the strongest challenge reactivity. The reason for this finding is unclear. Perhaps as individuals may have a fundamental need to belong to groups (Tajfel \& Turner, 1979; Turner et al., 1987), they do too with leaders, with the exception of when the leader is a direct rival (i.e., with whom followers feel low RI). To explain, it could be that participants in the neutral condition created a moderate connection with the leader $(M=3.29)$, autonomously, that in turn was most adaptive for $\mathrm{CV}$ reactivity (even compared to high RI with the leader). In this pressurized situation where participants may have felt somewhat isolated they may have sought connection with the leader on their own terms and perhaps it was this autonomous action that engendered the most adaptive challenge $\mathrm{CV}$ reactivity in the neutral condition. An alternative explanation is that there may be a curvilinear effect, where moderate RI with the leader is optimal, which could be investigated by researchers in the future. Further, in the current studies we focused on the level of RI 
1 participants reported with a leader, but it's not known on what basis the relationship did (or did

2 not) have psychological meaning. Based on the social identity approach, and given the nature of the manipulation, it's likely that participants identified (or not) with the leader because they represented the in-group (e.g., in the high RI condition) or the out-group (e.g., in the low RI condition). Future research is required to further investigate these postulations, which may go some way to explain why organizations typically prefer to appoint external (non-affiliated) consultants during times of stress (e.g., during organizational change). By nature, non-affiliated leaders have no psychological ties with group members and therefore are potentially more willing to drive through change.

\section{Practical Implications}

Extending previously evidenced links between RI with the leader and supervisor-related job performance (Zhu et al., 2015), current findings show that high RI with the leader is crucial for followers' intentional task mobilization. Our findings additionally show that if followers perceive low RI this is likely to elicit a maladaptive, threat $\mathrm{CV}$ reactivity when approaching stressful situations. This is a valuable implication because stress is ubiquitous in leadership and performance situations (e.g., as shown by the predictive links between workplace stress and CV disease; Kivimäki et al., 2012), and our findings demonstrate that leaders have a crucial role to play in followers' CV responses to pressurized tasks. It is important to note that RI is in the eye of the follower. The 4R's process recently proposed by Slater, Evans, and Turner (2016), which builds on Haslam et al's (2011) 3R's postulations, may provide a useful framework for leaders to avoid the deleterious effects of low RI. Haslam and colleagues 3R's outlined a framework of: (1) Reflecting; (2) Representing; and (3) Realizing, to develop and enhance a shared sense of collective identity. Related to Studies 2 and 3, Slater and colleagues more recent development 
1 suggests that the achievement of $3 R$ process is likely to produce a positive Reappraisal $\left(4^{\text {th }} \mathrm{R}\right)$ in

2 followers during times of stress.

\section{Study Limitations and Future Research Directions}

$4 \quad$ The current studies are not without limitations. The studies focused on acute leadership

5 situations where the task is imminent, and further, in Studies 2 and 3 the leader was only

6 introduced to participants immediately prior to the task. Whilst the findings provide valuable

7 contributions to the social identity approach to leadership and health, and challenge and threat

8 theory, ultimately leadership success is determined over time. There would be contribution in

9 future longitudinal field investigations into the impact of RI with the leader on followers'

10 mobilization and CV reactivity. It should be noted too that the tasks used were laboratory-based

11 and may have limited relevance in the real-world. Therefore, we suggest that performance

12 findings should be treated with caution, nevertheless, these competitive tasks were imperative in

13 Studies 2 and 3 to elicit a stress response. In addition, from a challenge and threat perspective,

14 Study 3 provides the first examination of the effect of social identity leadership (and RI with the

15 leader specifically) on followers' CV reactivity, upon which future research should build (e.g.,

16 by examining elite athletes in natural performance settings) and challenge and threat theory

17 should account for in future developments.

\section{Conclusion}

The current research examined the neglected theoretical tenet of RI with the leader to

20 further understand successful leadership and the effect of RI on followers' psychophysiological

21 stress response. Collectively, findings provide evidence that differences in RI with the leader

22 manifest in follower intentional mobilization, resource appraisals, and CV reactivity when

23 approaching a motivated performance (pressurized) situation. In addition to developing, 
managing, and advancing a shared group identity, leaders must consider the deleterious effects of followers perceiving low RI with them. Current findings advance social identity and challenge and threat theoretical understanding by demonstrating such consideration is pertinent for leaders to achieve the cherished position of galvanizing their followers' mobilization, strengthening followers' resource appraisals, and avoiding a threat $\mathrm{CV}$ response to stress.

\section{References}

Aguinis, H., \& Bradley, K. J. (2014). Best-practice recommendations for designing and implementing experimental vignette methodology studies. Organizational Research Methods, 17, 351-371. doi: 10.1177/1094428114547952.

Berman, M.G., Jonides, J., \& Kaplan, S. (2008). The cognitive benefits of interacting with nature. Psychological Science, 19(12), 1207-1212. doi: 10.1111/j.1467-9280.2008.02225.

Blascovich, J., \& Mendes, W. B. (2000). Challenge and threat appraisals: The role of affective cues. In J. P. Forgas (Ed.) Feeling and thinking: The role of affect in social cognition (pp. 59-82). Paris: Cambridge University Press.

Blascovich, J., Mendes, W. B., Vanman, E., \& Dickerson, S. (2011). Social psychophysiology for social and personality psychology. London: Sage.

Blascovich, J., Seery, M. D., Mugridge, C. A,. Norris, K., \& Weisbuch, M. (2004). Predicting athletic performance from cardiovascular indexes of challenge and threat. Journal of Experimental Social Psychology, 40, 683-688. doi: 10.1016/j.jesp.2003.10.007

Boehm, S. A., Dwertmann, D. J. G., Bruch, H., \& Shamir, B. (2015). The missing link? Investigating organizational identity strength and transformational leadership climate as mechanisms that connect CEO charisma with firm performance. The Leadership Quarterly, 26, 156-171. http://dx.doi.org/10.1016/j.leaqua.2014.07.012. 
Brown, M. E., Treviño, L. K., \& Harrison, D. A. (2005). Ethical leadership: A social learning perspective for construct development and testing. Organizational Behavior and Human Decision Processes, 97(2), 117-134. http://dx.doi.org/10.1016/j.obhdp.2005.03.002.

Conroy, D. E., Elliot, A. J., \& Hofer, S. M. (2003). A $2 \times 2$ achievement goals questionnaire for sport: Evidence for factorial invariance, temporal stability, and external validity. Journal of Sport and Exercise Psychology, 25(4), 456-476. doi: http://dx.doi.org/10.1123/jsep.25.4.456

Dienstbier, R. A. (1989). Arousal and physiological toughness: Implications for mental and physical health. Psychological Review, 96, 84-100.

Geissner, S. R., \& van Knippenberg, D. (2008). “License to fail”: Goal definition, leader group prototypicality, and perceptions of leadership effectiveness after leader failure. Organizational Behaviour and Human Decision Processes, 105, 14-35.

Gerstner, C. R., \& Day, D. V. (1997). Meta-analytic review of leader-member exchange theory: Correlates and construct issues. Journal of Applied Psychology, 82(6), 827-844.

Greenaway, K., Haslam, S. A., Branscombe, N. R., Cruwys, T., Ysseldyk, R., \& Heldreth, C. (2015). From "we" to "me": Group identification enhances perceived personal control with consequences for health and well-being. Journal of Personality and Social Psychology, 109, 53-74. doi:org/10.1037/pspi0000019

Halevy, N., Berson, Y., \& Galinsky, A. D. (2011). The mainstream is not electable: When vision triumphs over representativeness in leader emergence and effectiveness. Personality and Social Psychology Bulletin, 37, 893-904.

Haslam, S. A. (2004). Psychology in organizations: The social identity approach. (2nd ed.). Thousand Oaks, CA: Sage Publications. 
Haslam, S. A., Jetten, J., Postmes, T., \& Haslam, C. (2009). Social identity, health and wellbeing: An emerging agenda for applied psychology. Applied Psychology: An International Review, 58(1), 1-23. doi: 10.1111/j.1464-0597.2008.00379.x

Haslam, S. A., \& Reicher, S. D. (2006). Stressing the group: Social identity and the unfolding dynamics of responses to stress. Journal of Applied Psychology, 91(5), 1037-1052. doi: 10.1037/0021-9010.91.5.1037

Haslam, S. A., Reicher, S. D., \& Platow, M. J. (2011). The new psychology of leadership: Identity, influence and power. Hove: Psychology Press.

Haussen, J. A., Kattenstroth, M., van Dick, R., \& Mojzisch, A. (2012). "We" are not stressed: Social identity in groups buffers neuroendocrine stress reactions. Journal of Experimental Social Psychology, 48, 973-977. doi:10.1016/j.jesp.2012.02.020

Hogg, M. A. (2001). A social identity theory of leadership. Personality and Social Psychology Review, 5, 184-200.

Jones, M. V., Meijen, C., McCarthy, P., \& Sheffield, D. (2009). A theory of challenge and threat states in athletes. International Review of Sport and Exercise Psychology, 2, 161-180. doi: 10.1080/17509840902829331.

Kivimäki, M., Nyberg, S. T., Batty, G. D., Fransson, E. I., Heikkilä, K., Alfredsson, L., ... Theorell, T. (2012). Job strain as a risk factor for coronary heart disease: A collaborative meta-analysis of individual participant data. The Lancet, 380, 1491-1497. http://dx.doi.org/10.1016/S0140-6736(12)60994-5

Moore, L. J., Vine, S. J., Wilson, M. R., \& Freeman, P. (2012). The effect of challenge and threat states on performance: An examination of potential mechanisms. Psychophysiology, 49(10), 1417-1425. doi: 10.1111/j.1469-8986.2012.01449.x 
Northouse, P. G. (2015). Leadership (6th ed.). Thousand Oaks, CA: Sage.

Perry, R. P., Hladkyj, S., Pekrun, R. H., \& Pelletier, S. T. (2001). Academic control and action control in the achievement of college students: A longitudinal field study. Journal of Education and Psychology, 93(4), 776-789. doi.org/10.1037/0022-0663.93.4.776

Seery, M. D. (2011). Challenge or threat? Cardiovascular indexes of resilience and vulnerability to potential stress in humans. Neuroscience and Biobehavioral Reviews, 35, 1603-1610 http://dx.doi.org/10.1016/j.neubiorev.2011.03.003.

Seyranian, V. (2014). Social identity framing communication strategies for mobilizing social change. The Leadership Quarterly, 25, 468-486. http://dx.doi.org/10.1016/j.leaqua.2013.10.013

Slater, M. J., Barker, J. B., Coffee, P., \& Jones, M. V. (2015). Leading for Gold: Social identity leadership processes at the London 2012 Olympic Games. Qualitative Research in Sport, Exercise, and Health, 7(2), 192-209. doi:10.1080/2159676X.2014.936030

Slater, M. J., Evans, A. L., \& Turner, M. J. (2016). Implementing a social identity approach for effective change management. Journal of Change Management, 16(1), 18-37. doi. $10.1080 / 14697017.2015 .1103774$

Sluss, D. M., \& Ashforth, B. E. (2007). Relational identity and identification: Defining ourselves through work relationships. Academy of Management Review, 32(1), 9-32. doi: 10.5465/AMR.2007.23463672.

Smith, C. T., \& De Houwer, J. (2014). The impact of persuasive messages on IAT performance is moderated by source attractiveness and likeability. Social Psychology, 45(6), 437-448.

Steffens, N., Haslam, S. A., \& Reicher, S. D. (2014). Up close and personal: Evidence that shared social identity is a basis for the 'special' relationship that binds followers to leaders. 
The Leadership Quarterly, 25, 296-313. doi:10.1016/j.leaqua.2013.08.008

Steffens, N. K., Haslam, S. A., Schuh, S., Jetten, J., \& van Dick, R. (2016). A meta-analytic review of social identification and health in organizational contexts. Personality and Social Psychology Review. doi:10.1177/1088868316656701

Subašić, E., Reynolds, K. J., Turner, J. C., Veenstra, K. E., \& Haslam, S. A. (2011). Leadership, power and the use of surveillance: Implications of shared social identity for leaders' capacity to influence. The Leadership Quarterly, 22, 170-181.

Tajfel, H., \& Turner, J. C. (1979). An integrative theory of intergroup conflict. In S. Worchel \& W. G. Austin (Eds.), The psychology of intergroup relations (pp. 33-47). Monterey, CA: Brooks-Cole.

Tomaka, J., Blascovich, J., Kibler, J., \& Ernst, J. M. (1997). Cognitive and physiological antecedents of threat and challenge appraisal. Journal of Personality and Social Psychology, 73, (1), 63-72. doi: 10.1037/0022-3514.73.1.63

Turner, J. C., Hogg, M. A., Oakes, P. J., Reicher, S., \& Wetherell, M. S. (1987). Rediscovering the social group: A self-categorisation theory. Oxford: Basil Blackwell.

Turner, M. J., Jones, M. V., Sheffield, D., \& Cross, S. L. (2012). Cardiovascular indices of challenge and threat states predict performance under stress in cognitive and motor tasks. International Journal of Psychophysiology, 86, 48-57. doi:10.1016/j.ijpsycho.2012.08.004 Turner, M. J., Jones, M. V., Sheffield, D., Slater, M. J., Barker, J. B., \& Bell, J. (2013). Who thrives under pressure? Predicting the performance of elite academy cricketers using the cardiovascular indicators of challenge and threat states. Journal of Sport and Exercise Psychology, 35(4), 387-397. 
1 Turner, M. J., Jones, M. V., Sheffield, D., Barker, J. B., \& Coffee, P. (2014). Manipulating cardiovascular indices of challenge and threat states using resource appraisals. International Journal of Psychophysiology, 94, 9-18. doi: 10.1016/j.ijpsycho.2014.07.004.

van Dijke, M., \& De Cremer, D. (2010). Procedural fairness and endorsement of prototypical leaders: Leader benevolence or follower control? Journal of Experimental Social Psychology, 46, 85-96.

van Knippenberg, B., \& van Knippenberg, D. (2005). Leader self-sacrifice and leadership effectiveness: The moderating role of leader prototypicality. The Journal of Applied Psychology, 90, 25-37. http://dx.doi.org/10.1037/0021-9010.90.1.25.

Zhu, W., He, H., Trevino, L. K., Chao, M. M., \& Wang, W. (2015). Ethical leadership and follower voice and performance: The role of follower identifications and entity morality beliefs. The Leadership Quarterly, 22, 702-718. http://dx.doi.org/10.1016/j.leaqua.2015.01.004 


\section{Footnote}

2

$3{ }^{1}$ To aid confidence in our manipulations we tested for unintended effects by showing an

4 independent sample of students $(n=30)$, from the same University, a picture of the three leaders

5 in a randomized sequence. Following Smith and De Houwer (2014), participants rated each

6 leader on: (1) attractiveness, (2) intelligence, (3) likeability, and (4) expertise on a 5-point scale

7 from 1 (not at all) to 5 (very). Four repeated-measures ANOVAs indicated attractiveness,

8 intelligence, likeability, and expertise did not vary significantly as a function of condition (high

9 RI vs. low RI vs. neutral; all $F$ 's $<0.40$ and all $p$ 's $>0.681$ ). 
1 Table 1.

2 Means, standard deviations, and correlations of all variables in Study 1.

\begin{tabular}{llcccccc}
\hline & Variable & Mean & S.D. & 1 & 2 & 3 & 4 \\
\hline 1 & In-group identification & 5.79 & 1.01 & - & & & \\
2 & Relational identification with leader & 4.50 & 1.32 & 0.20 & - & & \\
3 & Mobilization & 5.26 & 1.10 & $0.33^{*}$ & $0.55^{* *}$ & - & \\
4 & Hours & 10.13 & 4.18 & 0.16 & $0.26^{*}$ & $0.40^{* *}$ & - \\
5 & High RI & .50 & 0.50 & -0.04 & $0.62^{* *}$ & $0.41^{* *}$ & $0.21^{*}$ \\
\hline
\end{tabular}

3 Note. ${ }^{*} p<0.05$

$4 \quad * * p<0.001$.

5 High $\mathrm{RI}$ coded as a dummy variable $($ High $\mathrm{RI}=1$, Low $\mathrm{RI}=0)$. 
Table 2.

2 Means and standard deviations of all Study 2 variables across the high RI, low RI, and neutral conditions.

\begin{tabular}{lccc}
\multicolumn{1}{c}{ Variable } & High RI & Low RI & Neutral 4 \\
\hline In-group identification & $5.92 \pm 0.81$ & $5.69 \pm 0.93$ & $5.54 \pm 1.075$ \\
Out-group identification & $1.32 \pm 0.63$ & $1.62 \pm 0.80$ & $1.31 \pm 0.62$ \\
Relational identification with the leader & $3.68 \pm 0.99^{*}$ & $2.27 \pm 1.25$ & $2.52 \pm 1.17^{6}$ \\
Importance & $2.52 \pm 1.45$ & $2.65 \pm 1.35^{\#}$ & $1.73 \pm 1.197$ \\
Mobilization & $4.99 \pm 0.86^{* *}$ & $4.18 \pm 1.18$ & $3.69 \pm 1.07$ \\
PAp & $6.00 \pm 1.15^{* *}$ & $4.96 \pm 1.46$ & $4.42 \pm 1.74$ \\
MAp & $5.44 \pm 1.12^{* *}$ & $4.50 \pm 1.27$ & $4.00 \pm 1.55^{9}$ \\
PAv & $4.08 \pm 1.63^{*}$ & $3.62 \pm 1.96$ & $2.77 \pm 1.690$ \\
MAv & $4.24 \pm 1.98$ & $3.85 \pm 1.83$ & $3.77 \pm 1.82$ \\
Control & $5.20 \pm 1.04$ & $5.08 \pm 1.13$ & $4.73 \pm 1.19$ \\
Self-efficacy & $6.88 \pm 0.88^{* *}$ & $5.96 \pm 1.31$ & $5.65 \pm 1.212$ \\
Cognitive performance & $10.28 \pm 2.49^{* *}$ & $7.50 \pm 2.98$ & $7.46 \pm 3.443_{3}$ \\
Hours & $.88 \pm 1.09$ & $0.84 \pm 0.94$ & $0.72 \pm 1.31$ \\
Percentage (\%) effort & $57.4 \pm 41.86$ & $44.62 \pm 36.22$ & $39.21 \pm 43.98$ \\
\hline
\end{tabular}

Note. * Indicates difference between the high RI and neutral conditions only.

$17 * *$ Indicates difference between the high RI condition relative to low RI and neutral conditions.

18 " Indicates difference between the low RI and neutral conditions (at $p<0.05$ ). 
Table 3.

Means, standard deviations, and correlations of all variables in Study 2

\begin{tabular}{|c|c|c|c|c|c|c|c|c|c|c|c|c|c|c|c|c|c|c|}
\hline & Variable & Mean & S.D. & 1 & 2 & 3 & 4 & 5 & 6 & 7 & 8 & 9 & 10 & 11 & 12 & 13 & 14 & 15 \\
\hline 1 & IG ID & 5.71 & 0.94 & - & & & & & & & & & & & & & & \\
\hline 2 & OG ID & 1.42 & 0.70 & -0.18 & - & & & & & & & & & & & & & \\
\hline 3 & RI & 2.81 & 1.29 & 0.22 & 0.19 & - & & & & & & & & & & & & \\
\hline 4 & PAp & 5.12 & 1.60 & $0.45^{* *}$ & -0.19 & $0.29 *$ & - & & & & & & & & & & & \\
\hline 5 & PAv & 3.47 & 1.83 & $0.27^{*}$ & 0.21 & 0.15 & $0.56^{* *}$ & - & & & & & & & & & & \\
\hline 6 & MAp & 4.51 & 1.65 & $0.24^{*}$ & 0.10 & $0.31 *$ & $0.54 * *$ & $0.47 * *$ & - & & & & & & & & & \\
\hline 7 & MAv & 3.95 & 1.86 & 0.19 & 0.13 & $0.27^{*}$ & 0.22 & $0.33^{*}$ & $0.65^{* *}$ & - & & & & & & & & \\
\hline 8 & Cont & 4.96 & 1.21 & $0.26^{*}$ & -0.12 & -0.02 & $0.23 *$ & 0.06 & 0.16 & 0.03 & - & & & & & & & \\
\hline 9 & $\mathrm{SE}$ & 6.18 & 1.32 & $0.30 *$ & -0.11 & $0.23 *$ & $0.41 * *$ & $0.27 *$ & $0.31 *$ & 0.15 & $0.63 * *$ & - & & & & & & \\
\hline 10 & $\operatorname{Imp}$ & 2.30 & 1.38 & $0.26^{*}$ & 0.02 & 0.10 & $0.46^{* *}$ & $0.51 * *$ & $0.55^{* *}$ & $0.27^{*}$ & 0.15 & $0.25^{*}$ & - & & & & & \\
\hline 11 & Mob & 4.29 & 1.18 & $0.48 * *$ & -0.07 & $0.44 * *$ & $0.67 * *$ & $0.48 * *$ & $0.42 * *$ & $0.25^{*}$ & 0.07 & $0.35^{*}$ & $0.43^{* *}$ & - & & & & \\
\hline 12 & Hours & 0.82 & 1.11 & 0.15 & 0.13 & 0.17 & 0.15 & 0.15 & 0.09 & 0.13 & -0.11 & 0.01 & 0.14 & $0.33 *$ & - & & & \\
\hline 13 & Perf & 8.44 & 3.36 & -0.01 & 0.03 & 0.20 & 0.13 & -0.07 & $0.27^{*}$ & 0.14 & 0.14 & $0.30^{*}$ & 0.06 & 0.13 & 0.003 & - & & \\
\hline 14 & Effort & 46.94 & 40.98 & 0.11 & -0.01 & 0.06 & 0.21 & 0.16 & 0.13 & 0.10 & 0.08 & 0.17 & 0.20 & $0.25^{*}$ & $0.43 * *$ & 0.05 & - & \\
\hline 15 & High RI & 0.33 & 0.47 & 0.15 & -0.10 & $0.47 * *$ & $0.38^{*}$ & $0.23 *$ & $0.29 *$ & 0.11 & 0.12 & $0.41 * *$ & 0.11 & $0.42 * *$ & 0.04 & $0.39 * *$ & 0.18 & - \\
\hline 16 & Low RI & 0.34 & 0.48 & -0.02 & 0.21 & $-0.30 * *$ & -0.07 & 0.06 & -0.02 & -0.04 & 0.07 & -0.10 & 0.19 & -0.05 & 0.02 & -0.19 & -0.04 & $0.50 * *$ \\
\hline
\end{tabular}

Note. ${ }^{*} p<.05$

$* * p<.001$.

Key: IG ID = in-group identification, $\mathrm{OG} \mathrm{ID} \mathrm{=} \mathrm{out-group} \mathrm{identification,} \mathrm{RI}=$ leader relational identification, $\mathrm{PAp}=$ performance approach goals, $\mathrm{PAv}=$

performance avoidance goals, MAp = mastery approach goals, MAv = mastery avoidance goals, Cont $=$ perceived control, $\mathrm{SE}=$ self-efficacy, Imp $=$ task

importance, $\mathrm{Mob}=$ intentional mobilization, Hours $=$ future hours, Perf $=$ task performance, Effort $=$ percentage effort $(\%)$ intentions, High RI $=$ condition coded

as a dummy variable (high $=1$, low and neutral $=0)$, Low $\mathrm{RI}=$ condition coded as a dummy variable $($ low $\mathrm{RI}=1$, high and neutral $=0)$. 


\section{RELATIONAL IDENTIFICATION AND STRESS REACTIVITY}

Table 4.

Means and standard deviations of all Study 3 variables across the high RI, low RI, and neutral conditions.

\begin{tabular}{lccc}
\hline \multicolumn{1}{c}{ Variable } & High RI & Low RI & Neutral \\
\hline In-group identification & $5.81 \pm 1.27$ & $6.17 \pm 0.87$ & $6.07 \pm 1.25$ \\
Out-group identification & $1.54 \pm 1.30$ & $1.54 \pm 1.18$ & $1.71 \pm 1.33$ \\
Relational identification with the leader & $4.23 \pm 1.66^{*}$ & $2.50 \pm 1.59$ & $3.29 \pm 1.65$ \\
Importance & $3.08 \pm 0.89$ & $2.96 \pm 1.12$ & $2.57 \pm 1.20$ \\
Challenge/threat index & $-0.14 \pm 1.25$ & $-0.68 \pm 1.98$ & $0.76 \pm 1.83^{\#}$ \\
Cognitive function & $5.96 \pm 1.46$ & $6.21 \pm 1.56$ & $6.18 \pm 1.96$ \\
\hline
\end{tabular}

Note. * Indicates difference between the high RI and low RI conditions $(p<0.05)$.

${ }^{*}$ Indicates difference between the neutral and low RI conditions $(p<0.05)$. 


\section{RELATIONAL IDENTIFICATION AND STRESS REACTIVITY}

Table 5.

Means, standard deviations, and correlations of all variables in Study 3

\begin{tabular}{|c|c|c|c|c|c|c|c|c|c|c|}
\hline & Variable & Mean & S.D. & 1 & 2 & 3 & 4 & 5 & 6 & 7 \\
\hline 1 & In-group identification & 5.71 & 0.94 & - & & & & & & \\
\hline 2 & Out-group identification & 1.42 & 0.70 & 0.08 & - & & & & & \\
\hline 3 & Relational identification with leader & 2.81 & 1.29 & $0.36^{*}$ & $0.39 * *$ & - & & & & \\
\hline 4 & Importance & 5.12 & 1.60 & $0.25 *$ & -0.16 & 0.13 & - & & & \\
\hline 5 & Performance & 3.47 & 1.83 & -0.001 & -0.03 & -0.08 & -0.10 & - & & \\
\hline 6 & Challenge and threat index & 4.51 & 1.65 & -0.09 & -0.07 & 0.09 & 0.08 & -0.02 & - & \\
\hline 7 & High RI & 3.95 & 1.86 & -0.13 & -0.04 & $0.35^{*}$ & 0.14 & -0.07 & -0.06 & - \\
\hline 8 & Low RI & 4.96 & 1.21 & 0.09 & -0.03 & $-0.33 *$ & 0.06 & 0.04 & $-0.26^{*}$ & $-0.47 * *$ \\
\hline
\end{tabular}

Note. ${ }^{*} p<0.05$.

$* * p<0.001$.

High $\mathrm{RI}=$ condition coded as a dummy variable (high $=1$, low and neutral $=0)$, Low $\mathrm{RI}=$ condition coded as a dummy variable $($ low $\mathrm{RI}=1$, high and neutral $=$ $0)$. 